\title{
$X$ chromosome gene dosage as a determinant of congenital malformations and of age-related comorbidity risk in patients with Turner syndrome, from childhood to early adulthood
}

\author{
Elodie Fiot' ${ }^{1}$, Delphine Zénaty', Priscilla Boizeau ${ }^{2,3}$, Jérémie Haignere ${ }^{2,3}$, Sophie Dos Santos ${ }^{1}$ and \\ Juliane Léger ${ }^{1,4}$ on behalf of the French Turner Syndrome Study Group ${ }^{\dagger}$
}

${ }^{1}$ Assistance Publique-Hôpitaux de Paris, Robert Debré University Hospital, Pediatric Endocrinology Diabetology Department, Reference Centre for Endocrine Growth and Development Diseases, Paris, France, ${ }^{2}$ AP-HP, Hôpital Robert Debré University Hospital, Unit of Clinical Epidemiology, Paris, France, ${ }^{3}$ Inserm, CIC-EC 1426, Paris, France, ${ }^{4}$ Université de Paris, Institut National de la Santé et de la Recherche Médicale (INSERM), UMR 1141, DHU Protect, F-75019 Paris, France

Correspondence should be addressed to J Léger Email juliane.leger@aphp.fr

\begin{abstract}
Objective: Turner Syndrome is associated with several phenotypic conditions associated with a higher risk of subsequent comorbidity. We aimed to evaluate the prevalence of congenital malformations and the occurrence of age-related comorbid conditions and to determine whether the frequencies of congenital and acquired conditions depend on X chromosome gene dosage, as a function of karyotype subgroup.

Design and methods: This national retrospective observational cohort study includes 1501 patients. We evaluated the prevalence of congenital malformations and the cumulative incidence of subsequent specific comorbidities at five-year intervals, from the ages of 10 to 30 years, with stratification by karyotype subgroup: $45, X(n=549), 45$, X/46, isoXq $(n=280), 46, X, r(X) / 46, X X(n=106), 45, X / 46, X X(n=221)$, presence of $Y(n=87)$.

Results: Median age was 9.4 (3.7-13.7) years at first evaluation and 16.8 (11.2-21.4) years at last evaluation. Congenital heart (18.9\%) malformations were more frequent in $45, X$ patients, and congenital renal (17.2\%) malformations were more frequent in $45, X, 45, X / 46$, isoXq and $46, X, r(X) / 46, X X$ patients than in those with $45, X / 46, X X$ mosaicism or a $Y$ chromosome $(P<0.0001)$. The cumulative incidence of subsequent acquired conditions, such as thyroid disease, hearing loss, overweight/obesity, dyslipidemia and, to a lesser extent, celiac disease, glucose intolerance/type 2 diabetes, hypertension and liver dysfunction increased with age, but less markedly for patients with mosaicism than for those with other karyotypes. Patients with a ring chromosome were more prone to metabolic disorders. Conclusion: These data suggest that $\mathrm{X}$ gene chromosome dosage, particularly for Xp genes, contributes to the risk of developing comorbidities.
\end{abstract}




\section{Introduction}

Turner syndrome (TS) is a condition in which all or part of one $\mathrm{X}$ chromosome is absent from some or all cells; it affects approximately one in every 2500 liveborn girls (1). The most frequently reported features are growth retardation with short adult stature and gonadal dysgenesis. TS may be associated with various congenital or acquired diseases $(1,2,3,4,5)$. Mortality, due to cardiovascular conditions in particular, and morbidity are much higher in TS patients than in the general population.

The most frequently observed karyotypes are $45, \mathrm{X}$ (40-50\%) and the 45,X/46,XX mosaic karyotype (15-25\%). Karyotypes with an $\mathrm{X}$ isochromosome $(45, \mathrm{X} / 46$,isoXq or $45, \mathrm{X} / 46$,isoXp), a $\mathrm{Y}$ chromosome, $\mathrm{X}$ ring chromosome or deletions of the $\mathrm{X}$ chromosome are less frequent $(6,7)$. Most of the clinical traits of TS are due to the haploinsufficiency of various genes on the X chromosome, particularly those in the pseudoautosomal regions (PAR 1 and PAR 2), which normally escape the physiological process of $\mathrm{X}$ inactivation, although other regions may also be implicated (8).

The role of the SHOX gene in the short stature of patients with TS is well established (9). However, little is known about the relationship between genes and associated diseases in TS, and the effect of karyotype on the prevalence of comorbidities remains a matter of debate (10). Most studies to date have focused on small transverse series of patients of different ages and had only small numbers of patients in the different karyotype subgroups $(11,12,13,14,15,16,17,18,19,20)$. Improvements in our knowledge of the associations between genetic abnormalities and phenotype in patients with TS would facilitate assessments of the risk of complications in each patient, thereby improving patient support and potentially leading to targeted therapies.

We recently demonstrated an association between karyotype subgroup and spontaneous growth and adult height after growth hormone (GH) treatment, with spontaneous growth more strongly affected in patients with 46,X,r(X)/46,XX, 45,X/46, isoXq and 45, X karyotypes than in those with mosaicism or with a $\mathrm{Y}$ chromosome. We also showed that GH therapy does not decrease the association between karyotype and adult height deficit, highlighting the major role of the $\mathrm{X}$ chromosome in growth, not only for spontaneous growth but also after height improvement due to GH therapy. These findings suggest that haploinsufficiency for as yet unidentified Xp genes increases the risk of a larger height deficit in patients with TS (21).
In this study, we evaluated the prevalence of congenital malformations and the risk of developing acquired diseases, such as autoimmune thyroid disease, celiac disease, hearing loss, overweight/obesity, glucose intolerance/type 2 diabetes, dyslipidemia, hypertension and liver dysfunction, relative to age at onset, in a large cohort of patients with TS and in various karyotype subgroups.

\section{Patients and methods}

\section{Patients}

This national, multicenter, observational study included all patients $(n=1536)$ with TS diagnosed up to January 2013 and followed at pediatric and adult centers from the French National Rare Disease Network participating in the study. TS was diagnosed prenatally in 254 patients (17\%), at birth in $220(14 \%)$, and age at diagnosis was unknown for 24 patients (1.5\%). Median age (25-75th percentile) at diagnosis for the 1038 patients diagnosed postnatally was $10.0(6.1-13.3)$ years. Median age for the total cohort was $9.4(3.7-13.7)$ years at first evaluation and 16.8 (11.2-21.4) years at last evaluation. Median follow-up was $4.1(0.0-11.0)$ years, and $188(12 \%)$ of the patients were over the age of 30 years at their last evaluation. Estrogen supplementation was introduced at the age of 13.8 (12.7$15.2)$ years in 665 of the $832(80 \%)$ adolescent patients, and spontaneous menarche occurred in 242 of 809 (30\%) adolescent patients.

Patients were classified into six subgroups on the basis of karyotype: $45, \mathrm{X}(n=549,36 \%), 45, \mathrm{X} / 46$,isoXq $(n=280$, $19 \%), 46, \mathrm{X}, \mathrm{r}(\mathrm{X}) / 46, \mathrm{XX}(n=106,7 \%), 45, \mathrm{X} / 46, \mathrm{XX}(n=221$, $15 \%)$, presence of $\mathrm{Y}(n=87,6 \%)$ and other karyotypes, including various mosaicism with triple $X$, various $X p$ or Xq deletions and various complex rearrangements or translocations within an X chromosome $(n=258,17 \%)$. Patients with unknown karyotypes $(n=35)$ were excluded from the study (Fig. 1).

\section{Protocol}

Data were collected from medical records, on standardized data collection forms completed retrospectively for the time of TS diagnosis, and then at 5-year intervals thereafter, for all patients $(n=1501)$. The presence of congenital malformations was evaluated by analyzing data from clinical and radiological examinations performed at the initial evaluation. Age at the occurrence of acquired 


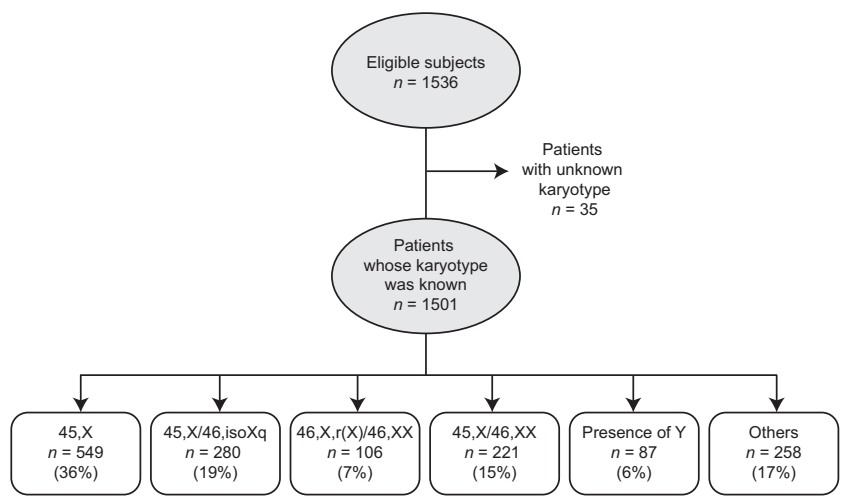

\section{Figure 1}

Flow chart of patients.

diseases was recorded for diseases first identified during follow-up, until the age of 30 years, based on analyses of clinical, laboratory and radiological evaluations.

This observational study was approved by the Paris Nord Ethics Review Committee for Biomedical Research Projects (CEERB) $\left(\mathrm{N}^{\circ}\right.$ 12-029) and the National French data protection authority (Commission Nationale de l'Informatique et des Libertés, CNIL, No. 909474 in 2010). In accordance with French law, patients, older children and young adults were informed of the use of routinely collected medical data and asked whether they were opposed to this use.

\section{Methods}

The genetic analyses carried out included standard karyotype analyses of more than 20 cells or fluorescence in situ hybridization analysis with centromeric probes for the $\mathrm{X}$ and $\mathrm{Y}$ chromosomes on about 100 studied cells in 829 patients, karyotype analyses of fewer than 20 cells in 243 patients and the type of analysis carried out was unknown for 429 patients. Congenital heart and kidney malformations were ruled out by ultrasonography. Autoimmune thyroid disease was defined as subclinical or overt hypothyroidism/hyperthyroidism on the basis of serum thyroid hormone levels (thyroid-stimulated hormone, free thyroxine levels) and/or levothyroxine or antithyroid drug treatment and/or the presence of serum thyroid autoantibodies (antithyroid peroxidase, antithyroglobulin, thyroid-stimulating immunoglobulin). Celiac disease was defined as the presence of tissue transglutaminase antibody or deamidated gliadin peptide antibody. Hearing loss was assessed by audiometric evaluations ( $\geq 30$ decibels) and it was noted whether the patient displayed hearing impairment in one or both ears, conductive or sensorineural hearing loss and whether a hearing aid was used. Overweight and obesity were defined according to Cole's standards for patients aged 2-18 years (22), and as a BMI greater than 25 and $30 \mathrm{~kg} / \mathrm{m}^{2}$, respectively, in patients over the age of 18 years. Glucose intolerance was defined as a blood glucose level $2 \mathrm{~h}$ after glucose ingestion in an oral glucose tolerance test of between $140(7.8 \mathrm{mmol} / \mathrm{L})$ and $199 \mathrm{mg} / \mathrm{dL}(11.0 \mathrm{mmol} / \mathrm{L})$ and diabetes as a fasting blood glucose level of $126 \mathrm{mg} / \mathrm{dL}$ $(7.0 \mathrm{mmol} / \mathrm{L})$ or higher during an oral glucose tolerance test or the use of antidiabetic medication. Dyslipidemia was defined as the presence of hypercholesterolemia (a fasting cholesterol concentration $>5.2 \mathrm{mmol} / \mathrm{L}$ ) and/or hypertriglyceridemia (a fasting triglyceride concentration $>1.5 \mathrm{mmol} / \mathrm{L}$ ) or the use of lipid-lowering therapy. Hypertension was defined as a blood pressure above the normal range for age and sex (23) or on the basis of treatment with antihypertensive drugs. Liver dysfunction was confirmed by hepatic enzyme (alanine aminotransferase, aspartate aminotransferase, gammaglutamyltransferase) levels above the normal range.

\section{Statistical analysis}

The prevalence of congenital malformations is expressed as absolute numbers (percentages). The characteristics of patients with congenital malformations (heart and kidney) were compared between karyotype subgroups (45,X, 45,X/46,isoXq, 46,X,r(X)/46,XX, 45,X/45,XX, presence of $\mathrm{Y}$ and other subgroups) in chi-squared tests. Kaplan-Meier cumulative incidence estimates and 95\% confidence intervals were calculated for each acquired comorbidity, from the age of 10-30 years. Data were censored at the study end date, on January 31, 2013. We first used the data for all patients $(n=1501)$ to analyze autoimmune thyroid disease, celiac disease, hearing loss, overweight/obesity, glucose intolerance/type 2 diabetes, dyslipidemia, hypertension and liver dysfunction. The data were then analyzed with stratification for the five well-defined karyotype subgroups $(45, \mathrm{X}, 45, \mathrm{X} / 46$,isoXq, $46, \mathrm{X}, \mathrm{r}(\mathrm{X}) / 46, \mathrm{XX}, 45, \mathrm{X} / 46, \mathrm{XX}$, presence of $\mathrm{Y})$. Patients with other karyotypes $(n=258)$ were not included in this analysis due to the considerable heterogeneity of this group, with only small numbers of patients presenting each of the different karyotypes included within it. Missing data were not adjudicated.

All tests were two-tailed, and values of $P<0.05$ were considered statistically significant. The analysis was performed with SAS software version 9.4 (SAS Institute Inc.). 


\section{Results}

\section{Congenital malformations}

The prevalence of congenital heart and kidney malformations was evaluated in all patients $(n=1501)$. Such malformations were found in 18.9 and $17.2 \%$, respectively (Table 1). Heart malformations were more frequent in $45, \mathrm{X}$ patients, and kidney malformations were more frequent in $45, \mathrm{X}, 45, \mathrm{X} / 46$,isoXq and $46, \mathrm{X}, \mathrm{r}(\mathrm{X}) / 46, \mathrm{XX}$ patients than in patients with other karyotypes $(P<0.0001)$.

\section{Acquired diseases}

The cumulative incidence of comorbidities increased over time - this gradual increase being most marked for autoimmune thyroid disease, hearing loss and overweight/obesity and less marked for dyslipidemia, liver dysfunction, celiac disease, glucose intolerance/type 2 diabetes and hypertension (Fig. 2). The occurrence of autoimmune thyroid disease increased from 5\% $(95 \%$ confidence interval, CI, 4-7\%) to $46 \%$ (42-51\%), that of hearing loss increased from $10 \%(8-12 \%)$ to $45 \%(40-$ $49 \%)$ and that of overweight/obesity increased from $8 \%$ (6-10\%) to $60 \%(55-65 \%)$. Occurrences increased from $3 \%$ (2-4\%) to $23 \%$ (19-28\%) for dyslipidemia, from $2 \%$ (1-3\%) to $27 \%$ (23-31\%) for liver dysfunction, from $2 \%$ (1-2\%) to 6\% (4-9\%) for celiac disease, from 1\% (0-1\%) to $10 \%(7-13 \%)$ for glucose intolerance/type 2 diabetes and from $2 \%(1-3 \%)$ to $8 \%(5-10 \%)$ for hypertension, between the ages of 10 and 30 years.

The cumulative incidence of comorbidities in the five karyotype subgroups is shown in Fig. 3 and Table 2 . Comorbidities were more prevalent among patients with structural abnormalities of the $\mathrm{X}$ chromosome, such as those with a ring chromosome and $45, X / 46$,isoXq, whereas phenotypes were milder in $45, \mathrm{X} / 46, \mathrm{XX}$ patients and in those with a $\mathrm{Y}$ chromosome. Patients with a $45, \mathrm{X}$ karyotype tended to be affected similarly to those with a ring chromosome or the $45, \mathrm{X} / 46$,isoXq karyotype, in terms of hearing loss and thyroid disease. Patients with a ring chromosome had a higher prevalence of glucose intolerance/type 2 diabetes and hypertension than those in the other karyotype subgroups.

When patients for whom the diagnostic method used for karyotyping analyses was unknown $(n=429)$ were excluded from the analysis, the prevalence of congenital malformations and the cumulative incidence rates of comorbidities were similar between groups 


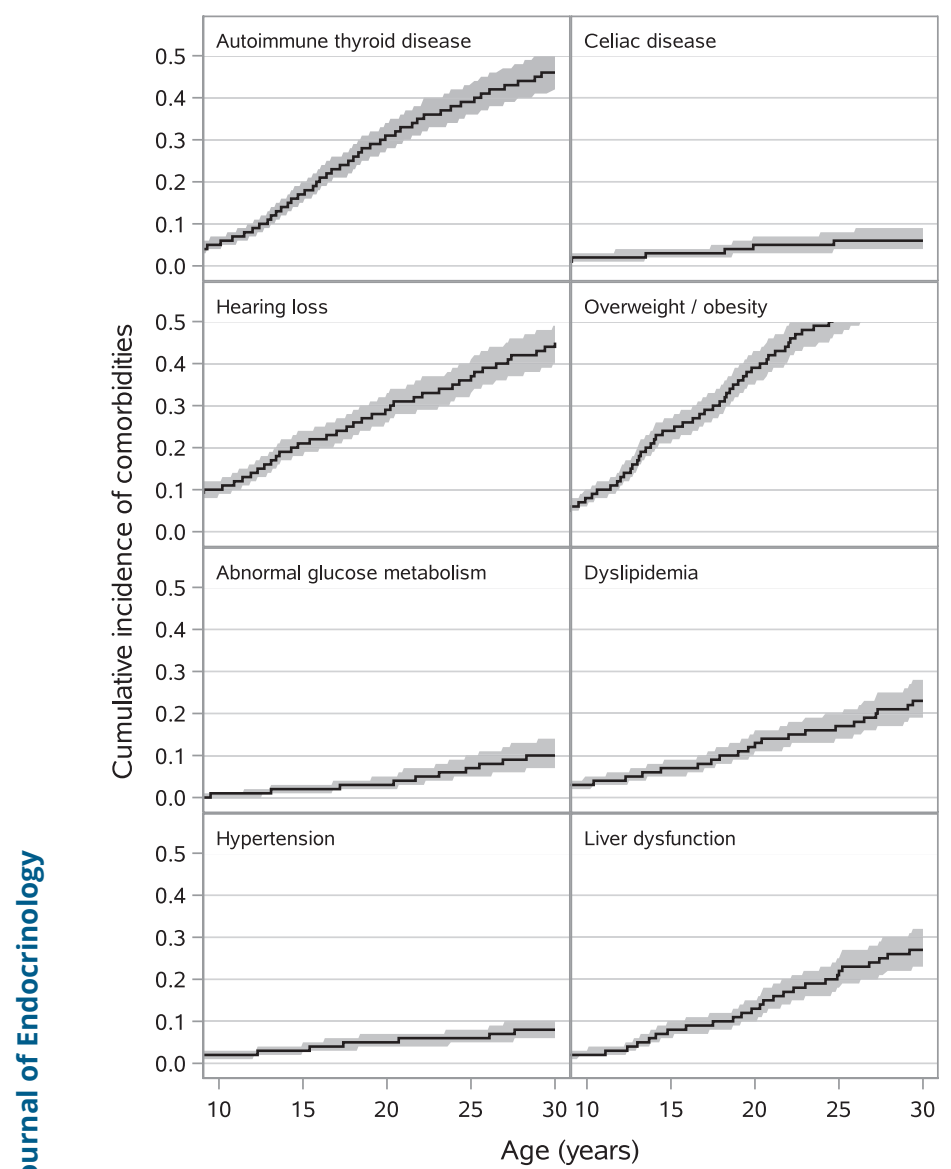

\section{Figure 2}

Kaplan-Meier estimates of the cumulative incidence (and 95\% confidence interval) of the development of comorbid conditions, including autoimmune thyroid disease, celiac disease, hearing loss, overweight/obesity, glucose intolerance/ type 2 diabetes, dyslipidemia, hypertension and liver dysfunction, in patients with Turner Syndrome.

(Supplementary data, Supplementary Fig. 1 and Supplementary Tables 1, 2, see section on supplementary data given at the end of this article).

\section{Discussion}

The results of this observational multicenter study, on one of the largest cohorts of patients with TS ever studied longitudinally, extend our knowledge about the increase in prevalence with age of acquired conditions associated with TS, from childhood to early adulthood. Attempts have been made to quantify the age-related increase in all types of comorbidities in TS in transverse studies $(15,24,25)$. However, this is the first time that the pattern of morbidities has been extensively studied over time in

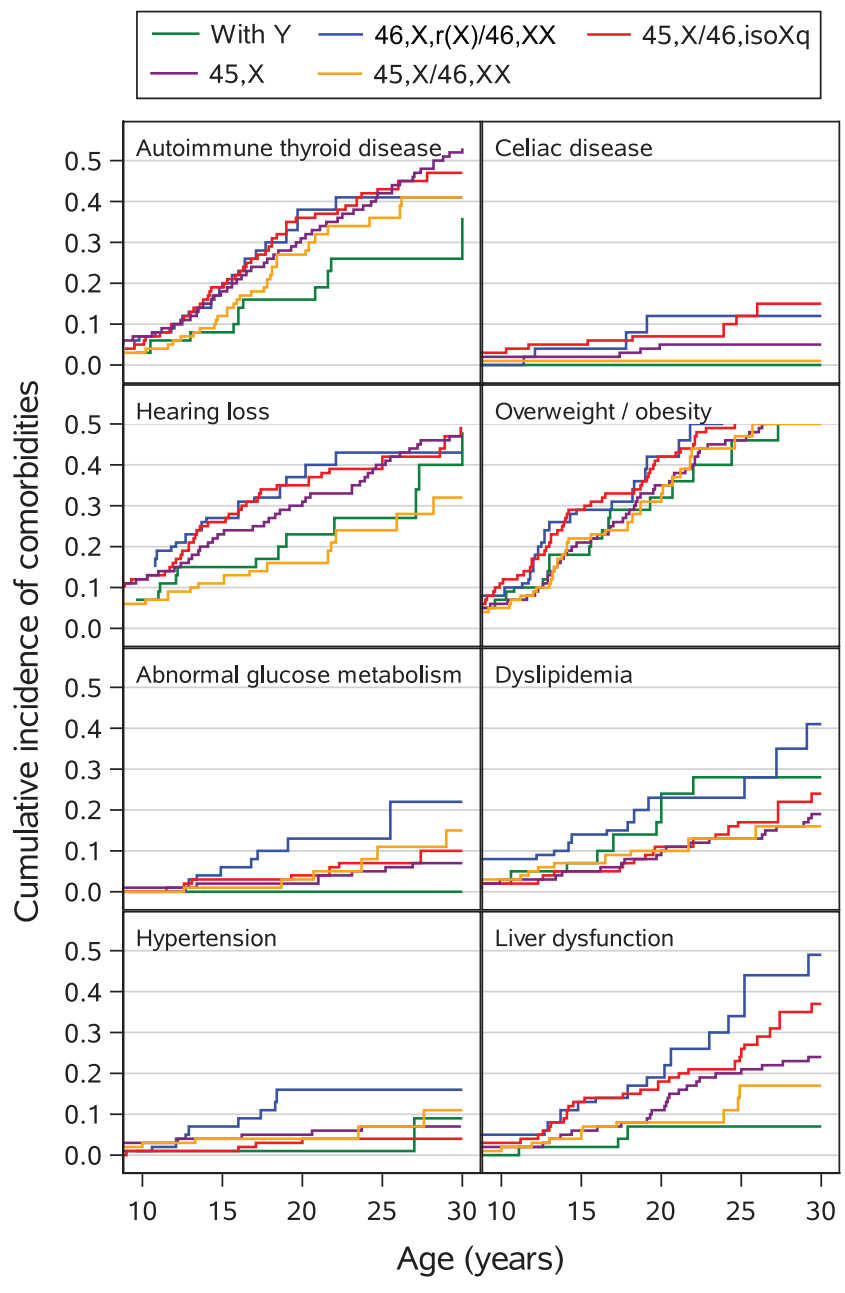

Figure 3

Kaplan-Meier estimates of the cumulative incidence of the development of comorbid conditions, including autoimmune thyroid disease, celiac disease, hearing loss, overweight/ obesity, glucose intolerance/type 2 diabetes, dyslipidemia, hypertension and liver dysfunction in patients with Turner Syndrome, by karyotype subgroup. (The incidence of the comorbidities is not known in a French reference population between the ages of 10-30 years.)

a large nationwide study in a population of young TS patients. One of the interesting findings of this study was the lower prevalence of comorbidities in patients with $45, \mathrm{X} / 46, \mathrm{XX}$ mosaicism or with a $\mathrm{Y}$ chromosome than in those with a ring chromosome or with a $45, \mathrm{X} / 46$,isoXq or $45, \mathrm{X}$ karyotype, highlighting the major role of $\mathrm{X}$ chromosome dosage in the occurrence of comorbidities in these patients.

The importance of $\mathrm{X}$ chromosome gene dosage as a risk factor for congenital and acquired comorbid conditions was not previously recognized in some studies, 


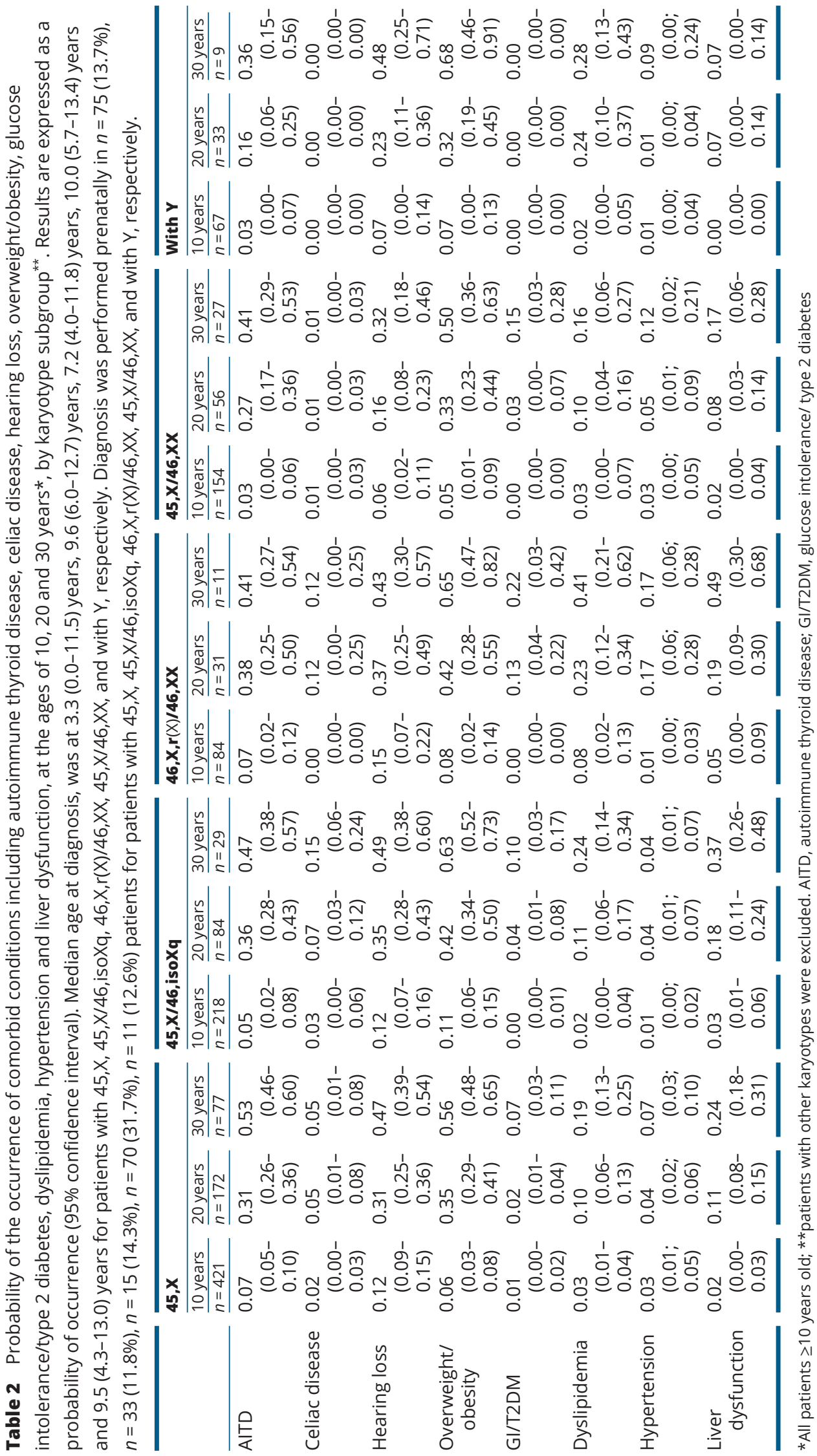


as the relatively small number of patients studied and differences in patient age made it difficult to describe the complete spectrum according to karyotype accurately $(11,12,13,14,15,16,17,18,19,20,26,27)$. For acquired conditions, some studies focused on pediatric patients only $(12,16,20)$, whereas others analyzed young or middle-aged women $(14,28,29,30,31)$. Moreover, with few exceptions $(26,27,32,33,34,35)$, most of these studies were transverse in nature, precluding the evaluation of age at onset for each comorbidity and the relationship to the different karyotypes.

Our findings for the prevalence of heart malformations in 45 , X patients are consistent with those of other studies (36). The prevalence of renal malformations in the various karyotype subgroups remains a matter of debate. Some studies have reported a higher prevalence of such malformations only in 45 , X patients $(11,12,37)$, whereas others found no difference between karyotype subgroups (13), and we found an excess of renal malformations not just in $45, \mathrm{X}$ patients, but also in $46, \mathrm{X}, \mathrm{r}(\mathrm{X}) / 46, \mathrm{XX}$ and $45, \mathrm{X} / 46$, isoXq patients in this study.

Consistent with most $(17,25,35,37)$, but not all previous studies $(26,27,29,32,38)$, autoimmune thyroid disease was more frequently observed in $45, \mathrm{X} / 46$,isoXq and 45 , $\mathrm{X}$ patients. Our findings also provide the first precise information about the increase in celiac disease frequency with age in patients with $45, \mathrm{X} / 46$,isoXq, $46, \mathrm{X}, \mathrm{r}(\mathrm{X}) / 46, \mathrm{XX}$ and $45, \mathrm{X}$ karyotypes. This association has never before been reported in previous studies (18, 39). It has been suggested that a gene on the long arm of the $\mathrm{X}$ chromosome may play a pathogenic role in the development of autoimmune disease and that an imbalance between loci on the short and long arms of the $\mathrm{X}$ chromosome may also increase the risk of immune dysfunction (25). The haploinsufficiency of $\mathrm{X}$ chromosome genes, causing a lack of self-antigen exposure in the thymus, may also increase the risk of autoimmunity (17).

Contrary to one previous study reporting no relationship (40), our findings on hearing impairment are consistent with those of other previous studies reporting a higher frequency of such impairment in patients with 45 , X and 45,X/46,isoXq karyotypes (41). However, none of the previous studies reported a high frequency of hearing impairment in patients with a ring X chromosome similar to that reported here.

Another important finding of our study is the association of the $46, \mathrm{X}, \mathrm{r}(\mathrm{X}) / 46, \mathrm{XX}$ karyotype with metabolic conditions, including overweight/obesity, glucose intolerance/type 2 diabetes, dyslipidemia, hypertension and liver dysfunction. Dyslipidemia was also associated with karyotypes including a Y chromosome, and liver dysfunction and overweight/obesity were associated with the $45, X / 46$,isoXq karyotype. Previous studies have reported an association between metabolic conditions and the 45 , X karyotype $(20,42)$ and have suggested that mosaicism protects against cardiovascular risk $(19,43)$. Bakalov et al. (31) found that the prevalence of diabetes mellitus was significantly higher in 45 , $X$ patients than in patients with other karyotypes, but even higher in women with monosomy for $\mathrm{Xp}$ coupled with trisomy for $\mathrm{Xq}$ (delXp and isoXq), suggesting that haploinsufficiency for $\mathrm{Xp}$ genes increases the risk of diabetes mellitus and that excess dosage for Xq genes compounds the risk. Calanchini et al. also reported a higher prevalence of abnormal liver function tests in patients with the isoXq karyotype (44). Our findings are consistent with those of a recent study showing a trend toward a higher incidence of diabetes mellitus, hypertension and liver dysfunction in patients with the ring X karyotype (28). The pathophysiological mechanism underlying this observation remains unclear, but overweight and obesity may contribute to the onset of metabolic disorders in this subgroup of patients with TS.

Some non-pseudoautosomal genes escape inactivation and may be involved in the pathogenesis of TS. Our data suggest that haploinsufficiency of the genes located on Xp that are normally expressed for both sex chromosome is involved in the stronger predisposition to comorbid conditions. The mechanism by which the haploinsufficiency of loci on the Xp chromosome results in weaker gene expression remains unclear. Changes in gene expression may differ between cell and tissue types, but this variation may have contributed significantly to the phenotypic variation observed in our study. An additive effect on associated genes within a given gene network, with alterations to gene expression triggered by epigenetic factors, has been suggested (43).

The strengths of this observational longitudinal cohort study with extensive national coverage include the large number of pediatric patients and young adults with TS for whom comprehensive data were collected, with several disease-related covariables available for a large proportion of patients, making it possible to evaluate the increase in the rates of comorbidity development with age in the various karyotype subgroups and to evaluate infrequent karyotype subgroups, such as the rare $46, \mathrm{X}, \mathrm{r}(\mathrm{X}) / 46$, XX subgroup.

However, this study also had several inherent limitations, due to its observational and retrospective nature and the heterogeneity of study subjects, who were 
diagnosed at various ages, from the neonatal period into adulthood. The prevalence of complications, including arterial hypertension in particular, may also have been underestimated due to incomplete ascertainment or not investigated as rigorously as recommended in clinical practice (7), as recently demonstrated in France and the Netherlands $(45,46)$. However, it seems unlikely that this would have resulted in a substantial misclassification bias, given that incomplete ascertainment would have been similar between the karyotype subgroups studied, with a large number of patients in each group. We did not evaluate the detection and prevalence of acquired cardiac abnormalities, which may affect almost onethird of patients (47), as the quality of diagnosis and the frequency of echocardiographic imaging differed too much between centers, with the use of different definitions of anatomical defects. Karyotyping was carried out on blood samples, but it remains unclear whether exclusive monosomy $\mathrm{X}$ applies to all tissues, as some degree of mosaicism has been observed, potentially accounting for the phenotypic variability between TS individuals with the same karyotype according to blood sample analyses. Nevertheless, it is widely accepted that routine karyotype analyses on 20 cells are sufficient to detect mosaicism down to levels of about 5\% (6). The method used to detect mosaicism in our patients should, therefore, have been sufficiently sensitive in most cases. However, in some cases, karyotyping was carried out in routine laboratory analysis more than 25 years before our study. The absence of information about the diagnostic method (unknown) or the use of non-standard methods of karyotype analysis (analyses on fewer than 20 cells) in some patients may have lowered the precision of the analyses, as the percentage of mosaicism was slightly lower and that of monosomy $\mathrm{X}$ higher in these patients than in those for whom more than 20 cells were analyzed in a standard manner, but it seems unlikely that this would have resulted in a substantial misclassification bias, given the large number of patients studied. We attempted to minimize selection bias by assessing a broad population of patients, but some selection bias may have remained and may have affected the accuracy of disease prevalence estimates, as patients not followed at endocrinology centers were not evaluated. We cannot rule out the possibility of residual selection bias due to the non-inclusion of patients not followed at endocrinology centers, but we assume that such a bias would not have had a differential effect on misclassification. However, we cannot rule out the possibility of such differential misclassification, which might have biased estimates in either direction. Finally, our cohort was relatively young, as patients were followed predominantly at pediatric centers rather than at adult endocrinology centers, which made it difficult to evaluate a large number of older patients. Further studies are required to explore changes with aging, to determine whether differences in acquired conditions associated with TS persist to the same extent in different patients and karyotype subgroups and whether the degree of mosaicism modulates phenotype.

In conclusion, this study provides further insight into the age-related increase in the incidence of acquired comorbidities and the relationship between the prevalence of congenital malformations, acquired diseases and karyotype subgroups in TS. Our findings highlight the role of $\mathrm{X}$ chromosome gene dosage in the genesis of diseases associated with TS, resulting in a higher risk of comorbid conditions in patients with the $45, \mathrm{X}, \quad 45, \mathrm{X} / 46$,isoXq and 46,X,r(X)/46,XX karyotypes and a lower risk in patients with mosaic karyotypes, such as $45, \mathrm{X} / 46, \mathrm{XX}$ or $\mathrm{XY}$ mosaic karyotypes, suggesting an important role of $\mathrm{Xp}$ genes. Further studies are required to characterize these genes to determine the pathogenic pathways involved and to clarify other possible roles of epigenetic mechanisms in the development of comorbidities associated with TS (43). The potential onset of comorbid conditions should be carefully assessed in all patients, but our findings highlight the utility of precision medicine for facilitating the identification of patients at high risk of developing particular complications, such as metabolism disorders in patients with ring chromosomes and providing opportunities for personalized surveillance and prevention strategies, which may eventually reduce the significant morbidity associated with outcome.

\section{Supplementary data}

This is linked to the online version of the paper at https://doi.org/10.1530/ EJE-18-0878.

\section{Declaration of interest}

J Léger is an editor of the journal (European Journal of Endocrinology) and was not involved in the review or editorial process for this paper, on which he/she is listed as an author. The other authors have nothing to disclose.

\section{Funding}

This study was supported in part by the French Ministry of Health (Rare Disease Plan). Data collection, analysis and interpretation and the decision to submit the paper for publication were the responsibility of the authors alone. The funding sources had no role in study design, data collection, data interpretation, data analysis or the writing of the report. 


\section{Acknowledgements}

The following participated in the French Turner Syndrome Study Group (French national rare disease network): J C Carel, S Cabrol, P Chanson, S Christin-Maitre, C Courtillot, B Donadille, J Dulon, M Houang, M Nedelcu, I Netchine, M Polak, S Salenave, D Samara-Boustani, D Simon, P Touraine, M Viaud (Paris); H Bony, K Braun, R Desailloud (Amiens); A M Bertrand, B Mignot, F Schillo (Besançon); P Barat (Bordeaux); V Kerlan, C Metz, E Sonnet (Brest); Y Reznik, V Ribault, (Caen); H Carla, I Tauveron (Clermont Ferrand); C Bensignor, F Huet, B Verges (Dijon); O Chabre, C Dupuis, A Spiteri (Grenoble); M Cartigny, C Stuckens, J Weill (Lille); A Lienhardt (Limoges); C Naud-Saudreau (Lorient); F Borson-Chazot, A Brac de la Perriere, M Pugeat (Lyon); T Brue, R Reynaud, G Simonin (Marseille); F Paris, C Sultan (Montpellier); B Leheup, G Weryha (Nancy); S Baron, B Charbonnel, S Dubourdieu (Nantes); E Baechler, P Fenichel, K Wagner (Nice); F Compain (Poitiers); H Crosnier, C Personnier (Poissy); B Delemer, A C Hecart, P F Souchon (Reims); M De Kerdanet, F Galland, S Nivot-Adamiak (Rennes); M Castanet, C Lecointre (Rouen); O Richard (Saint Etienne); N Jeandidier, S Soskin (Strasbourg); P Lecomte, M Pepin-Donat, P Pierre (Tours).

\section{References}

1 Gravholt CH, Juul S, Naeraa RW \& Hansen J. Morbidity in Turner syndrome. Journal of Clinical Epidemiology 199851 147-158. (https:// doi.org/10.1016/S0895-4356(97)00237-0)

2 Gravholt CH. Epidemiological, endocrine and metabolic features in turner syndrome. European Journal of Endocrinology 2004151 657-687. (https://doi.org/10.1530/eje.0.1510657)

3 Hjerrild BE, Mortensen KH \& Gravholt $\mathrm{CH}$. Turner syndrome and clinical treatment. British Medical Bulletin 200886 77-93. (https:// doi.org/10.1093/bmb/ldn015)

4 Pinsker JE. CLINICAL REVIEW: Turner syndrome: updating the paradigm of clinical care. Journal of Clinical Endocrinology and Metabolism 201297 E994-E1003. (https://doi.org/10.1210/jc.20121245)

5 Stochholm K, Juul S, Juel K, Naeraa RW \& Gravholt CH. Prevalence, incidence, diagnostic delay, and mortality in Turner syndrome. Journal of Clinical Endocrinology and Metabolism 200691 3897-3902. (https://doi.org/10.1210/jc.2006-0558)

6 Sybert VP \& McCauley E. Turner's syndrome. New England Journal of Medicine 2004351 1227-1238. (https://doi.org/10.1056/ NEJMra030360)

7 Gravholt CH, Andersen NH, Conway GS, Dekkers OM, Geffner ME, Klein KO, Lin AE, Mauras N, Quigley CA, Rubin K et al. Clinical practice guidelines for the care of girls and women with Turner syndrome: proceedings from the 2016 Cincinnati International Turner Syndrome Meeting. European Journal of Endocrinology 2017 177 G1-G70. (https://doi.org/10.1530/EJE-17-0430)

8 Zinn AR \& Ross JL. Turner syndrome and haploinsufficiency. Current Opinion in Genetics and Development 19988 322-327. (https://doi. org/10.1016/S0959-437X(98)80089-0)

9 Ross JL, Scott C Jr, Marttila P, Kowal K, Nass A, Papenhausen P, Abboudi J, Osterman L, Kushner H, Carter P et al. Phenotypes associated with SHOX deficiency. Journal of Clinical Endocrinology and Metabolism 200186 5674-5680. (https://doi.org/10.1210/ jcem.86.12.8125)

10 Miguel-Neto J, Carvalho AB, Marques-de-Faria AP, Guerra-Júnior G $\&$ Maciel-Guerra AT. New approach to phenotypic variability and karyotype-phenotype correlation in Turner syndrome. Journal of Pediatric Endocrinology and Metabolism 201629 475-479. (https://doi. org/10.1515/jpem-2015-0346)

11 Flynn MT, Ekstrom L, De Arce M, Costigan C \& Hoey HM. Prevalence of renal malformation in Turner syndrome. Pediatric Nephrology 1996 10 498-500. (https://doi.org/10.1007/s004670050148)
12 Bilge I, Kayserili H, Emre S, Nayir A, Sirin A, Tukel T, Bas F, Kilic G, Basaran S, Gunoz H et al. Frequency of renal malformations in Turner syndrome: analysis of 82 Turkish children. Pediatric Nephrology 2000 14 1111-1114. (https://doi.org/10.1007/s004670000315)

13 Al Alwan I, Khadora M, Amir I, Nasrat G, Omair A, Brown L, Al Dubayee M \& Badri M. Turner syndrome genotype and phenotype and their effect on presenting features and timing of diagnosis. International Journal of Health Sciences 20148 195-202. (https://doi. org/10.12816/0006086)

14 Verver EJ, Freriks K, Sas TC, Huygen PL, Pennings RJ, Smeets DF, Hermus AR, Menke LA, Wit JM, Otten BJ et al. Karyotype-specific ear and hearing problems in young adults with Turner syndrome and the effect of oxandrolone treatment. Otology and Neurotology 201435 1577-1584. (https://doi.org/10.1097/MAO.0000000000000406)

15 Oliveira CS, Ribeiro FM, Lago R \& Alves C. Audiological abnormalities in patients with Turner syndrome. American Journal of Audiology 201322 226-232. (https://doi.org/10.1044/10590889(2013/11-0027))

16 Bois E, Nassar M, Zenaty D, Léger J, Van Den Abbeele T \& Teissier N. Otologic disorders in Turner syndrome. European Annals of Otorhinolaryngology, Head and Neck Diseases 2018135 21-24. (https:// doi.org/10.1016/j.anorl.2017.08.006)

17 Hamza RT, Raof NA \& Abdallah KO. Prevalence of multiple forms of autoimmunity in Egyptian patients with Turner syndrome: relation to karyotype. Journal of Pediatric Endocrinology and Metabolism 2013 26 545-550. (https://doi.org/10.1515/jpem-2012-0265)

18 Bonamico M, Bottaro G, Pasquino AM, Caruso-Nicoletti M, Mariani P, Gemme G, Paradiso E, Ragusa MC \& Spina M. Celiac disease and Turner syndrome. Journal of Pediatric Gastroenterology and Nutrition 199826 496-499. (https://doi.org/10.1097/00005176199805000-00002)

19 Calcaterra V, Brambilla P, Maffè GC, Klersy C, Albertini R, Introzzi F, Bozzola E, Bozzola M \& Larizza D. Metabolic syndrome in Turner syndrome and relation between body composition and clinical, genetic, and ultrasonographic characteristics. Metabolic Syndrome and Related Disorders 201412 159-164. (https://doi.org/10.1089/ met.2013.0075)

20 Cicognani A, Mazzanti L, Tassinari D, Pellacani A, Forabosco A, Landi L, Pifferi C \& Cacciari E. Differences in carbohydrate tolerance in Turner syndrome depending on age and karyotype. European Journal of Pediatrics 1988148 64-68. (https://doi.org/10.1007/ BF00441818)

21 Fiot E, Zenaty D, Boizeau P, Haigneré J, Dos Santos S, Léger J \& French Turner Syndrome Study Group. X-chromosome gene dosage as a determinant of impaired pre and postnatal growth and adult height in Turner syndrome. European Journal of Endocrinology 2016 174 281-288. (https://doi.org/10.1530/EJE-15-1000)

22 Cole TJ, Bellizzi MC, Flegal KM \& Dietz WH. Establishing a standard definition for child overweight and obesity worldwide: international survey. BMJ 2000320 1240-1243. (https://doi.org/10.1136/ bmj.320.7244.1240)

23 Flynn JT, Kaelber DC, Baker-Smith CM, Blowey D, Carroll AE, Daniels SR, de Ferranti SD, Dionne JM, Falkner B, Flinn SK et al. Subcommittee on screening and management of high blood pressure in children. Clinical practice guideline for screening and management of high blood pressure in children and adolescents. Pediatrics 2017 140 e20171904. (https://doi.org/10.1542/peds.2017-1904)

24 Barrenäs ML, Nylén O \& Hanson C. The influence of karyotype on the auricle, otitis media and hearing in Turner syndrome. Hearing Research 1999138 163-170. (https://doi.org/10.1016/S03785955(99)00162-8)

25 Elsheikh M, Wass JA \& Conway GS. Autoimmune thyroid syndrome in women with Turner's syndrome - the association with karyotype. Clinical Endocrinology 200155 223-226. (https://doi.org/10.1046/ j.1365-2265.2001.01296.x) 
26 Livadas S, Xekouki P, Fouka F, Kanaka-Gantenbein C, Kaloumenou I, Mavrou A, Constantinidou N \& Dacou-Voutetakis C. Prevalence of thyroid dysfunction in Turner's syndrome: a long-term follow-up study and brief literature review. Thyroid 200515 1061-1066. (https://doi.org/10.1089/thy.2005.15.1061)

27 Gawlik A, Gawlik T, Januszek-Trzciakowska A, Patel H \& MaleckaTendera E. Incidence and dynamics of thyroid dysfunction and thyroid autoimmunity in girls with Turner's syndrome: a long-term follow-up study. Hormone Research in Paediatrics 201176 314-320. (https://doi.org/10.1159/000331050)

28 Cameron-Pimblett A, La Rosa C, King TFJ, Davies MC \& Conway GS The Turner syndrome life course project: karyotype-phenotype analyses across the lifespan. Clinical Endocrinology 201787 532-538. (https://doi.org/10.1111/cen.13394)

29 Hanew K, Tanaka T, Horikawa R, Hasegawa T \& Yokoya S. Prevalence of diverse complications and its association with karyotypes in Japanese adult women with Turner syndrome-a questionnaire survey by the Foundation for Growth Science. Endocrine Journal 201865 509-519. (https://doi.org/10.1507/endocrj.EJ17-0401)

30 Frost AR, Band MM \& Conway GS. Serological screening for coeliac disease in adults with Turner's syndrome: prevalence and clinical significance of endomysium antibody positivity. European Journal of Endocrinology 2009160 675-679. (https://doi.org/10.1530/ EJE-08-0846)

31 Bakalov VK, Cheng C, Zhou J \& Bondy CA. X-chromosome gene dosage and the risk of diabetes in Turner syndrome. Journal of Clinical Endocrinology and Metabolism 200994 3289-3296. (https://doi. org/10.1210/jc.2009-0384)

32 El-Mansoury M, Bryman I, Berntorp K, Hanson C, Wilhelmsen L \& Landin-Wilhelmsen K. Hypothyroidism is common in Turner syndrome: results of a five-year follow-up. Journal of Clinical Endocrinology and Metabolism 200590 2131-2135. (https://doi. org/10.1210/jc.2004-1262)

33 Lebenthal Y, Levy S, Sofrin-Drucker E, Nagelberg N, Weintrob N, Shalitin S, de Vries L, Tenenbaum A, Phillip M \& Lazar L. The natural history of metabolic comorbidities in Turner syndrome from childhood to early adulthood: comparison between 45 , X monosomy and other karyotypes. Frontiers in Endocrinology 20189 27. (https:// doi.org/10.3389/fendo.2018.00027)

34 Sybert VP. Cardiovascular malformations and complications in Turner syndrome. Pediatrics 1998101 E11. (https://doi.org/10.1542/ peds.101.1.e11)

35 Jørgensen KT, Rostgaard K, Bache I, Biggar RJ, Nielsen NM, Tommerup N \& Frisch M. Autoimmune diseases in women with Turner's syndrome. Arthritis and Rheumatism 201062 658-666. (https://doi.org/10.1002/art.27270)

36 Bondy C, Bakalov VK, Cheng C, Olivieri L, Rosing DR \& Arai AE. Bicuspid aortic valve and aortic coarctation are linked to deletion of the X chromosome short arm in Turner syndrome. Journal of Medical Genetics 201350 662-665. (https://doi.org/10.1136/ jmedgenet-2013-101720)
37 Lippe B, Geffner ME, Dietrich RB, Boechat MI \& Kangarloo H. Renal malformations in patients with Turner syndrome: imaging in 141 patients. Pediatrics 198882 852-856.

38 Bettendorf M, Doerr HG, Hauffa BP, Lindberg A, Mehls O, Partsch CJ, Schwarz HP, Stahnke N \& Ranke MB. Prevalence of autoantibodies associated with thyroid and celiac disease in Ullrich-Turner syndrome in relation to adult height after growth hormone treatment. Journal of Pediatric Endocrinology and Metabolism 200619 149-154. (https://doi.org/10.1515/JPEM.2006.19.2.149)

39 Bonamico M, Pasquino AM, Mariani P, Danesi HM, Culasso F, Mazzanti L, Petri A, Bona G, Italian Society of Pediatric Gastroenterology Hepatology (SIGEP) \& Italian Study Group for Turner Syndrom (ISGTS). Prevalence and clinical picture of celiac disease in Turner syndrome. Journal of Clinical Endocrinology and Metabolism 2002 87 5495-5498. (https://doi.org/10.1210/jc.2002-020855)

40 Bergamaschi R, Bergonzoni C, Mazzanti L, Scarano E, Mencarelli F, Messina F, Rosano M, Iughetti L \& Cicognani A. Hearing loss in Turner syndrome: results of a multicentric study. Journal of Endocrinological Investigation 200831 779-783. (https://doi. org/10.1007/BF03349257)

41 Lim DB, Gault EJ, Kubba H, Morrissey MS, Wynne DM \& Donaldson MD. Cholesteatoma has a high prevalence in Turner syndrome, highlighting the need for earlier diagnosis and the potential benefits of otoscopy training for paediatricians. Acta Paediatrica 2014103 e282-e287. (https://doi.org/10.1111/apa.12622)

42 El-Mansoury M, Barrenäs ML, Bryman I, Hanson C, Larsson C, Wilhelmsen L \& Landin-Wilhelmsen K. Chromosomal mosaicism mitigates stigmata and cardiovascular risk factors in Turner syndrome. Clinical Endocrinology 200766 744-751. (https://doi. org/10.1111/j.1365-2265.2007.02807.x)

43 Álvarez-Nava F \& Lanes R. Epigenetics in Turner syndrome. Clinical Epigenetics 201810 45. (https://doi.org/10.1186/s13148-018-0477-0)

44 Calanchini M, Moolla A, Tomlinson JW, Cobbold JF, Grossman A, Fabbri A \& Turner HE. Liver biochemical abnormalities in Turner syndrome: a comprehensive characterization of an adult population. Clinical Endocrinology 201889 667-676. (https://doi.org/10.1111/ cen.13811)

45 Devernay M, Ecosse E, Coste J \& Carel JC. Determinants of medical care for young women with Turner syndrome. Journal of Clinical Endocrinology and Metabolism 200994 3408-3413. (https://doi. org/10.1210/jc.2009-0495)

46 Freriks K, Timmermans J, Beerendonk CC, Verhaak CM, NeteaMaier RT, Otten BJ, Braat DD, Smeets DF, Kunst DH, Hermus AR et al. Standardized multidisciplinary evaluation yields significant previously undiagnosed morbidity in adult women with Turner syndrome. Journal of Clinical Endocrinology and Metabolism 201196 E1517-E1526. (https://doi.org/10.1210/jc.2011-0346)

47 Yetman AT, Starr L, Sanmann J, Wilde M, Murray M \& Cramer JW. Clinical and echocardiographic prevalence and detection of congenital and acquired cardiac abnormalities in girls and women with the Turner syndrome. American Journal of Cardiology 20189149 30840-30843.
Received 31 October 2018

Revised version received 2 April 2019

Accepted 16 April 2019 